\title{
Challenges Faced and Support Received: Older Adults' Perceptions of Hurricane Sandy
}

\author{
Allison R. Heid, PhD; Seran Schug, PhD; Francine P. Cartwright, BS; Rachel Pruchno, PhD
}

\section{ABSTRACT}

Objective: Individuals exposed to natural disasters are at risk for negative physical and psychological outcomes. Older adults may be particularly vulnerable; however, social support can act as a resource to help individuals respond to severe stressors. This study explored the challenges older people faced before, during, and after Hurricane Sandy in October 2012 and the people they turned to for support.

Methods: Semi-structured interviews were conducted with 20 older adults in New Jersey drawn from the ORANJ BOWL (Ongoing Research on Aging in New Jersey - Bettering Opportunities for Wellness in Life) research panel, who experienced high levels of primary home damage during Hurricane Sandy. Content analysis of interview transcripts classified older adults' perceptions on how they "made it" through - the challenges they faced and the support they received.

Results: The findings suggested that older adults experienced emotional, instrumental, social, and financial challenges before, during, and after the storm. However, by relying on family and friends, as well as neighbors and community networks, older people were able to respond to stressors.

Conclusions: Our findings carry implications for ensuring that older adults are connected to social networks before, during, and after disasters. The role of neighbors is particularly important when disasters strike. (Disaster Med Public Health Preparedness. 2017;11:39-47)

Key Words: Hurricane Sandy, older adults, qualitative, disaster

$\mathrm{H}$ urricane Sandy, a superstorm that hit the northeastern portion of the United States in October 2012, had wide-ranging effects on many individuals. ${ }^{1}$ As the largest Atlantic hurricane on record, Sandy destroyed homes, damaged property, and caused losses of heat, power, and water. ${ }^{2,3}$ Older individuals in New Jersey were particularly affected; $65 \%$ of people who died were over age $60 .{ }^{4}$

Given the context of aging (ie, decreases in biological ability, increased need for support), ${ }^{5}$ as individuals grow older they may experience an increased vulnerability to negative physical or psychological outcomes following a disaster; however, research is mixed. ${ }^{6,7}$ During times of distress, such as an environmental disaster, support from others is particularly important. ${ }^{8}$ Access to instrumental and social support and resources may determine why some older individuals fare better than others. ${ }^{9,10}$ Research has yet to fully understand how social support unfolds for older adults in the context of a disaster, specifically, how older adults perceive support and create support networks in the context of the storm and to whom older individuals turn before, during, and after a disaster. Although family support is important to older people, when electricity and communications are disrupted and older adults are disconnected from their traditional social networks, ${ }^{11}$ reliance on neighbors and community services may become paramount. This article took an in-depth approach to understanding the challenges older people faced before, during, and after Hurricane Sandy and the people and institutions they turned to for support.

\section{The Impact of a Natural Disaster on Older Adults}

Natural disasters can result in adverse circumstances and negative physical and psychological outcomes for those exposed..$^{12}$ Research has documented a wide variety of hassles, losses, and needs that people face when a disaster strikes. These include safety and security issues, lack of access to basic resources, communication difficulties, and transportation concerns. ${ }^{13}$ People may experience loss or damage of their homes, personal possessions, medications, or food. ${ }^{14} \mathrm{Or}$, individuals may face affronts to dignity, feelings of distress, or challenges with service delivery. ${ }^{15}$ Such challenges may set individuals up for long-term negative outcomes with regard to physical health, as well as their sense of security and psychological well-being.

As individuals age, they transition from what is considered the third old age of functioning well to 
the fourth old age characterized by decline. ${ }^{5}$ This shift is a person-specific process that can happen at any time for individuals (ie, age 60 or age 90) and aligns with increased biological and social vulnerability. The onset of a natural disaster during this time can result in negative outcomes for some older adults but not all. ${ }^{10,16-18}$ For example, older people (aged $\geq 65$ years and aged $51-68$ years) exposed to the 2008 Wenchuan earthquake in China demonstrated an increased risk for developing post-traumatic stress disorder and longer recovery trajectories when compared with younger people. ${ }^{7,19}$ However, other research illustrates that vulnerability may be linked to pre-storm demographic characteristics $^{7,9,20,21}$ (ie, gender, marital status, income) or health. ${ }^{6,12,22}$ Older adults who lack physical and psychological capacities or resources before a disaster may be at greater risk after the disaster. ${ }^{23}$

\section{Role of Social Support in Older Adults' Response to Disaster-Related Stressors}

The benefits of social support for managing the challenges associated with aging and managing stressors are well known. ${ }^{24,25}$ During a disaster, social support from family or friends may decrease the likelihood of negative outcomes. ${ }^{9,10}$ Such social support can be tangible or intangible, including instrumental support (ie, help with a task) or socio-emotional support (ie, having contact with someone or knowing someone is there if needed), and can empower older adults and build capacity for coping. ${ }^{26}$ Roberto and colleagues ${ }^{8}$ found that older people displaced by Hurricane Katrina had an increased reliance on their support network after the storm.

Yet, beyond family and friends, neighbors and larger community infrastructure may also be key for older individuals. ${ }^{10,27}$ Neighborhood social capital can act as a resource, supporting the ability of older people to manage stressors as well as their mental and physical health in the context of a disaster. ${ }^{28-33}$ Access to proximate support may become a distinguishing factor, identifying those older adults who are more resilient-able to positively respond to stressors-and those who may be vulnerable following a storm. ${ }^{9,10}$ People lacking a proximate network may be missing critical social infrastructure needed to weather a storm and recover.

\section{Taking a Qualitative Approach to Understanding Older Adults' Disaster Experiences}

In order to build understanding from a ground-up perspective and learn about individual-level experiences, qualitative methodologies are essential. Relying on the voice of participants through open-ended questions can provide valuable insight without introducing researcher bias. Past qualitative work has examined the impact of disasters on older adults' experiences. Ardalan and colleagues ${ }^{15}$ examined older adults' concerns in managing the Bam earthquake, Bauman $^{34}$ explored older adults' recollections of coping with
September 11, and Kamo and colleagues ${ }^{35}$ revealed perceptions of community change of older adults following Hurricane Katrina. Qualitative work has documented how older adults define losses, needs, hassles, and resilience following a disaster. ${ }^{13,14,36-38}$

\section{Current Study}

The objective of this study was to take an in-depth, qualitative approach to understanding the challenges that Hurricane Sandy presented to older people and to learn how older people identified and described the support they received from networks of family, friends, and neighbors before, during, and after the hurricane. We conducted openended interviews with older adults who had high levels of primary home damage in order to learn how older adults "made it" through the storm. Our research questions were as follows:

1) What emotional and instrumental challenges did older individuals face before, during, and after Hurricane Sandy?

2) Who did older adults turn to for support before, during, and after the storm in their traditional social networks (ie, family and friends) and how did these individuals support them?

3) How did neighbors or neighborhoods support older adults before, during, and after the disaster?

\section{METHODS \\ Sample}

Data were derived from the ORANJ BOWL (Ongoing Research on Aging in New Jersey - Bettering Opportunities for Wellness in Life) research panel. This panel $(N=5688)$ is a random-digit-dial sample of community-dwelling older adults in New Jersey who were first interviewed between November 2006 and April 2008, when they were aged 50 to 74 years (for sample details, see Pruchno et $\mathrm{al}^{39}$ ). Panelists completed questionnaires 8 to 33 months (whey they were aged 54 to 80 years) after Hurricane Sandy hit the northeastern portion of the United States in October of 2012. They reported on their level of home damage due to Hurricane Sandy as "none," "a little," or "a lot." Participants who reported "a lot" of home damage to their primary homes were considered eligible to participate in an additional open-ended interview regarding their experiences. Of 117 possible participants with "a lot" of home damage, the first 20 who agreed to participate and had damage to their primary homes were consented and enrolled in this qualitative study. Data saturation was achieved; common themes were present and repeated across interviews. The 20 participants did not differ from the other 97 nonparticipating individuals with "a lot" of home damage with regard to age, education, income, gender, marital status, or race. The present sample comprised 16 women and 4 men, most of whom were non-Hispanic white $(n=17)$; the participants' mean age when Sandy hit was 67.6 years $(\mathrm{SD}=7.1$; range, $56-79)$. The sample was 


\section{TABLE 1}

\begin{tabular}{lc}
\hline Participant Characteristics $^{\mathbf{a}}$ & \\
Demographic Characteristic & Mean or Percentage \\
& \\
Age at time of Hurricane Sandy, mean (SD), y & $67.60(7.09)$ \\
Race (non-Hispanic white), \% (n) & $85(17)$ \\
Gender (female), \% (n) & $80(16)$ \\
Marital status (married), \% (n) & $55(11)$ \\
Education, \% (n) & \\
2 years of college or less & $55(11)$ \\
$\quad 4$ years of college or more & $45(9)$ \\
Baseline income, \% (n) & \\
$\quad$ Less than \$30K & $15(3)$ \\
\$30K-\$80K & $30(6)$ \\
More than \$80K & $40(8)$
\end{tabular}

${ }^{\mathrm{a}} N=20$.

split regarding education and income with about half of participants reporting 4 years of college or more $(n=9)$ and income of more than $\$ 80,000(n=8)$, and the other half reporting 2 years of college or less $(n=11)$ and income of less than $\$ 80,000(n=9)$. See Table 1 for sample descriptive statistics. Home damage ranged from complete destruction caused by flooding to trees falling through roofs; no standard definition of damage was required beyond self-endorsement of "a lot" of damage.

\section{Procedures}

The authors' Institutional Review Board approved all data collection procedures. The qualitative interviews, completed by a trained bachelor's level research assistant, were conducted by phone $(n=10)$ or in person $(n=10)$, depending on each participant's preference. Interviews were audiorecorded and transcribed and lasted an average of 42 minutes (range, 22 to 96 minutes). Participants were compensated with a $\$ 10$ gift.

\section{Measures}

\section{Demographic Characteristics}

Participants reported their age, education, race, gender, marital status, and income at their baseline assessment for ORANJ BOWL (2006-2008).

\section{Semi-Structured Interview}

This study used an in-depth, semi-structured interview with participants to understand their experiences before, during, and after Hurricane Sandy. Questions included: Tell me about your experiences during Hurricane Sandy. What happened? What physical and emotional challenges did you face during this time? Did others help you during the storm? Sometimes when a natural disaster like Hurricane Sandy happens, it draws neighbors closer. Other times, it pulls people apart. What happened in your neighborhood? The interviewer used follow-up questions and prompts to encourage respondents to elaborate on answers.

\section{Data Preparation and Analysis Plan}

Interviews were transcribed, double-checked, and read by the authors and 2 trained undergraduate students using an opencoding process to produce a base coding tree that reflected the manifest content of the interviews (following content analysis strategies). ${ }^{40}$ The team met weekly to discuss and develop a list of agreed upon core codes following an iterative process in line with constant comparative techniques. ${ }^{41,42}$ This inductive approach resulted in the development of broad coding schemes informed by the research questions (ie, challenges) that were then expanded as the most salient issues and common responses were identified through additional reading (ie, instrumental challenges). Categories were further refined as more specific subtopics became evident (ie, power loss, heat, flooding). Where lower levels of specificity could not be agreed upon by the team, the broader code was maintained to ensure future replicability of the findings. Codes were developed that captured each unique idea. ${ }^{40}$ Final codes identified types of challenges faced by the older individuals before, during, and after Sandy; the types of supports people identified as significant; and the attitudes people had about neighborhood support. The transcripts were then re-read and coded by the team utilizing the developed coding tree to ensure consistent application of codes. Each participant response that followed an interviewer prompt was treated as a unit of coding. The research team met weekly to flesh out the application of the coding scheme, coding $25 \%(n=5)$ of the interviews together. Three team members coded each of the additional 15 interviews. Discrepancies between coders were discussed and resolved by consensus. The coded interviews were entered into QSR NVIVO 10 (QSR International Pty Ltd), and coded instances were counted to develop a sense of magnitude for each phenomenon in the sample.

\section{RESULTS}

\section{Challenges Faced}

Participants reported instrumental, emotional, social, and financial challenges created by Hurricane Sandy. These challenges posed concerns for meeting the participants' everyday needs. Regarding instrumental challenges, the participants reported power loss, heat loss, difficulties getting in and out of their homes, cleaning up, timeliness of repairs, lack of information, trouble accessing food, flooding, disconnected phone lines, struggles preparing their home and belongings for the storm, and health. Regarding emotional challenges, participants described feelings of distress before, during, and after the storm, as well as surprise, worry, powerlessness, and stress. Participants discussed social challenges and managing the emotions of others, as well as general financial challenges and regulatory concerns. Table 2 includes descriptions of 


\section{TABLE 2}

\section{Challenges Faced As a Result of Hurricane Sandy}

\section{Challenge Description}

\section{Instrumental Challenges}

Power loss: Loss of power; dealing with darkness; includes challenges with hot water if loss of hot water connected to power source

Heat loss: Loss of heat and being cold; includes challenges with hot water if loss of hot water connected to heating source

Getting in and out of their home: Could not leave home or travel anywhere; no gas; could not get into or out of where their home was

Cleaning up: Physical challenges of cleaning up the debris and dealing with the damage; including how the damage was managed

Timeliness of repairs: Timeliness of repairs as a problem

Lack of information: Feeling cut off; not in the know; lack of information on the storm

Access to food: Discussions of challenges cooking, getting food, or preparing food

Flooding: Challenge of flooding; sewage issues caused by flooding

Phone: Loss of phone capability/need for charging

Preparation: Challenge of preparation work; moving things high up; moving things inside

Health: Health and sickness of self or others; includes injury; physical or mental health; medical needs not met or reference to need for medical support for vulnerable groups, including reference to pre-existing medical conditions; discussion of medical challenges caused or worsened by Sandy

\section{Emotional Challenges}

Distress (of respondent): Fear/Scared; feeling in danger or not feeling safe; sadness or upsetting or distressing emotions; reference to something being terrible, awful, or miserable

\section{Example}

Frequency,

$n$ citations

( $n$ transcripts)

"Over a week...we lost power from the storm but then we lost power because all the power lines were ripped from the house when the tree fell." (56-year-old woman, IDC 1008)

"It was so cold and so dark...we just hunkered down and stayed in our home ... it was so cold we were using anything we could find. We found sterno floating in the water. We popped the top from the sterno and warmed our fingers over that." (58-year-old woman, ID 1017)

"This street was blocked off for a while because a tree fell on that end and 2 fell on that end and one right next door." (78-year-old woman, ID 1020)

"I had to pay for a new roof basically... [the tree] came from the second floor down to the first floor bathroom, the night of the storm...I went to the bathroom I couldn't open the light. There was water dripping out of the light fixture, so I had a lot of damage. I had to fix the ceilings and I had to clean the rug upstairs dry, up all the water in the rug, and downstairs it was a mess." (69-year-old woman, ID 1016)

"What we started, when the reconstruction started in December and went through you know early December to mid-December, December $11^{\text {th }}$ to March $11^{\text {th }}$. So I mean that's not time you want to have no roof over your head." (69-year-old man, ID 1018)

"[The power company] never let you know what they were up to. You didn't know if you had an idea that it would take 5 days or 4 days or 10 days." (66-year-old woman, ID 1003)

"Cooking... we really didn't have any food because all the electricity went out and everything went bad." (58-year-old woman, ID 1017)

"The first high tide took water in the house flooded my car out." (58-year-old man, ID 1009)

"The kids had big things outside and we could plug in to their things, whatever you called those big chargers they had. So we could all go up maybe 10 blocks to charge them." (71-year-old woman, ID 1007)

"I brought my pots in, my flower pots. I had about 30 flower pots...I turned my furniture upside down my lawn furniture upside down." (66-year-old woman, ID 1003)

"My wife started going downhill, I guess depression... It affected her...she's had a shunt because she had water in the brain at one time...So we thought maybe that wasn't working right or whatever...we called an ambulance....and took her into the hospital to test and everything and the tests all showed...the shunt was working ok and possibly she had uh a stroke or something....and nobody really gave me an answer... We were afraid something might happen to her, she wasn't walking steady...and it continued it was she was getting worse...She fell down and hit her head on the wall... They did all kinds of CAT scans and this and that and nobody... have yet to this minute, ... turned around and told me you know whatever it is, they were all agreeing to brain damage...I attributed it all to the that damn storm." (73-year-old man, ID 1015)

"I have to say it was a little scary because we went for a walk and when it was announced we thought, well it would take a while you know? It would rain or whatever, or the sewer would come up or the water would come up, but it came very fast." (71-year-old woman, ID 1007)
$164(20)$ 


\section{Continued}

Surprise (of respondent): Surprise or shock experienced, including realization/reactions to damage; disbelief that the storm/magnitude of the storm would occur

Worry (of respondent): Discussion of worries or anxieties of the impact of Hurricane Sandy; nervousness about family, neighbors, friends, or other people, about primary or secondary homes, about loss of power, heat, damage or looting, or about pets

Powerlessness (of respondent): Feeling powerless or helpless due to nature, government, etc; no way to protect or prevent damage; feeling lack control over the situation; fate is determining everything

\section{Social Challenges}

General social challenges: Challenges within social roles; including duties to self and others, but also loneliness or isolation during the storm

Emotions of others: Others' emotional responses before, during, and after the storm

\section{Financial Challenges}

General financial challenges: Challenges related to finances and economic practicalities; cost of damages; challenge of fixed income - foregone vacation; challenges of affording repairs or fixing the damage; challenge of paying for repairs; lack of funds from insurance; challenges of selling home

Regulatory: New regulations to follow; had to raise home up due to damage in area or own home
"I mean when the tree hit, you know I mean it was it was a scary $33(12)$ experience, and then you know we're happy that we were okay because of the shock of what happening." (69-year-old man, ID 1018)

"Well I was worried about when the lights went out at $7 \mathrm{pm}$ and the storm was getting bad I was worried about my husband getting home." (64-year-old woman, ID 1002)

"I guess I don't know. I guess I don't even know if boarding up the windows would have stopped...the power of those waves. I mean according to law now you must be on these 30 foot stilts or something. I don't know." (69-year-old woman, ID 1006)

"I was there by myself and I had lost my husband just two years before." (78-year-old woman, ID 1004)

"I went back inside and my wife was yelling at me, 'Don't go out! Don't go out!" (69-year-old man, ID 1001)

"I'm a foot. ..too low I need to go up 2... but it's a 150,000 dollars ... I already got an estimate. I can't afford to do it." (66-year-old woman, ID 1013)

"They changed the code like three times. They... would give you a hard time about permits,... what was actually needed to be done uh versus what you have done already. They tell you one thing you had to do, you would do it. They come back and go, 'That's not right."' (58-year-old man, ID 1009)

${ }^{a} N=20$ older adults in New Jersey reporting "a lot" of primary home damage.

${ }^{b}$ Frequencies of presentation of themes are listed for descriptive purposes only and are listed as the number of coded instances of text within a given number of transcripts.

${ }^{\mathrm{C}} \mathrm{ID}$ numbers in parentheses following a quote indicate re-coded participant ID numbers to allow the reader to identify quotes from the same source.

each type of challenge, example passages, and descriptive frequencies.

\section{How Older Adults' Social Networks of Families and Friends Supported Them}

Older adults described receiving support from their family members and friends before $(n=6)$, during $(n=12)$, and after $(n=11)$ Hurricane Sandy struck. Support included instances of physical or instrumental support, such as offering a place to stay, providing hot meals, or helping to clean up debris, and contact or social-emotional support, such as checking in with one another.

Physical support included providing a place to stay, which was provided by daughters, a mother, a son, sisters, and a brother. It also included weathering the storm together if the individuals lived together (ie, spouses) or stayed together, stopping by to check in, checking on the participant's home after the storm hit, and helping clean up the damage.

"My sister and her family managed to get a house to rent on the other side of our town and they got electricity back first...so on the really cold nights, I would go and...sleep at her place on the mattress over there... and I could take showers over there...That's basically how I survived." (58-year-old woman, ID 1017)

Socio-emotional support was provided by spouses, children, sisters, granddaughters, mothers, nieces, and nephews. Participants described talking to family members for support and reassurance during the storm.

"I called my sister... and she was experiencing the same thing. [Interviewer: She helped you during the storm?]... Absolutely." (61-year-old woman, ID 1019)

Friends were called upon for support less frequently before $(n=1)$, during $(n=1)$, and after the storm $(n=7)$. Friends provided a place to stay, helped clean up debris, provided contractor support with repairs, ran errands, and provided socio-emotional support through contact and conversations.

"People I didn't even know showed up at my house plus my two friends and helped [clean up debris]...I mean everything 
was first of all total chaos, everything was upended." (62-year-old woman, ID 1012)

"I called my friend and I said, 'What do you think I should do?"' (77-year-old woman, 1014)

\section{How Neighbors and Neighborhoods Supported Older Adults}

Beyond family and friends, participants described calling upon neighbors for support before $(n=7)$, during $(n=10)$, and after $(n=18)$ the storm. Physical support from neighbors included a wider variety of tasks than those provided by family members or friends, including providing a place to stay, helping to find a hotel room, cleaning up debris, giving money for food, providing food, cooking meals together, driving to the store together, getting coffee, offering visits for heat or while repairs were completed, and helping with groceries.

Socio-emotional support from neighbors was more frequently discussed than socio-emotional support from family and friends both before and after the storm.

"Neighbors started coming out of the houses and I remember people trying to help each other to clear their driveways so you could get your cars out." (66-year-old woman, ID 1003)

"Everybody was just making sure everybody else was ok." (58-year-old man, ID 1009)

"Everybody had their windows up...we [were] peeking at each other, waving, or coming out on steps because after...it stopped raining and there was no lights, like everybody was outside." (60-year-old woman, ID 1010)

In some cases, support was received from the local community and volunteers. Local community support included the area's local government or town support, including interactions with police officers and government/community officials. The majority of town support came through evacuation notices $(n=6)$, although others talked of interactions after the storm owing to restricted access to their communities $(n=4)$, cleanup support $(n=2)$, and accessing shelters $(n=2)$. Volunteers provided support with charging cell phones, shelter, food, drink, clothing, baby bottles, wood for woodburning stoves, door-to-door mental health services, debris cleanup, financial assistance, and repairs.

"There were volunteers in my neighborhood and they came in and worked on my hot water heater... and the Red Cross was here and there were other people that were bringing food around...the outpouring of volunteers was phenomenal, I never in my life would have thought so many people from so many walks of life and so many towns that were not affected by Sandy, people came from out of state." (58-year-old woman, ID 1017)
Participants additionally described the unique ways in which communities and neighbors supported them during the hardships of Sandy by describing the impact of the storm on "friendliness" ( $n=14$ participants) as critical to their response and recovery.

"You know neighbors were nice to each other I do have to say, young people all helpful, somebody really needed help, they helped each other. So that was a good thing." (71-yearold woman, ID 1007)

"Everybody was...very helpful, if they saw you struggling with appliances or carpet, people would stop and help you." (66-year-old woman, ID 1013)

"With my neighborhood...it didn't matter if you knew anybody, you would walk and talk to someone on the street and say, 'Are you ok?', because nobody was ok." (62-yearold woman, ID 1012)

However, this friendliness was described as an immediate coming together in a collective effort to respond to the stressors of the storm during the initial days, weeks, and months following Sandy. This increased friendliness and sociality dissipated over time, with interactions returning to typical patterns of individualism before the storm.

"We were extremely tight. We were all out in the street together...We were always...friendly anyway, but we were even more so directly after the storm. Now that people have rebuilt and are moving back in, the people that came back, I'd say it went back to how it was before." (58-year-old woman, ID 1017)

"Then once things got back into normal routine, it returned to way it was before." (69-year-old man, ID 1001)

"For a time, and after that everybody fell back off...I didn't see much difference in the people after that, after the first few weeks, after everybody got the street clean." (78-year-old woman, ID 1020)

\section{DISCUSSION}

Older adults who experienced home damage due to Hurricane Sandy experienced a variety of instrumental, emotional, social, and financial challenges. To respond to these challenges, they turned to traditional support networks including family and friends, as well as broader community support from neighbors, volunteers, and community organizations. Neighborhood connections immediately following Hurricane Sandy proved critical in supporting the physical and emotional response of older adults, above and beyond that provided by family members and friends. The results of this study illustrate the importance of social support systems, including neighbors, for older adults following a severe stressor such as a natural disaster. These results carry implications for research and practice. 
First, the findings are consistent with prior research and demonstrate that individuals experience a breadth of challenges when responding to a disaster. ${ }^{13,14}$ The results confirm research indicating that social support is critical in helping individuals respond to negative ramifications of a disaster, such as damage or lack of ability to meet everyday needs. ${ }^{9,10}$ Social support networks provide a resource that individuals can draw upon for instrumental support and reassurance. ${ }^{26}$ Participants in this study reached out to their family and friends for support as well as their communities. Findings provide information about whom older adults actually called upon and what types of tasks required support (instrumental or socio-emotional). Yet, although the context of aging presupposes a need for increased reliance on others in order to cope with the biological changes of aging, ${ }^{5}$ a reliance on others during a disaster is not unique to older adults. Further research should explore if there is a distinction between the challenges older individuals face and support they seek compared to younger adults to further understand older adults' resilience capacity and how we can bolster resources for people in need.

Results expand prior work by articulating the critical and unique role neighbors and neighborhoods can play in supporting older individuals in the face of a disaster. More specifically, although support from neighbors did not replace the support provided by family members, neighbor and community support was key for older adults before, during, and after Hurricane Sandy. In fact, neighbors, as a spontaneously generated support networks, were described by participants as providing a greater variety of instrumental and social-emotional supports and assistance than families and friends. Prior research documents that neighborhood social capital can be both structural and cognitive whereby structural components result in network extension and access to resources and cognitive components elicit processes such as trust. $^{43,44}$ In times of a disaster, the structural component of social capital may bolster individual-level access to needed resources and care, while the cognitive support may allow for socio-emotional coping.

Participants described a shift in neighborhood attitudes to an environment of friendliness and reciprocity immediately following the storm. This shift was perceived as critical to "weathering" the storm. However, this coming together was short-lived. Disasters may evoke a time of prosocial behavior-whether a given individual can provide help in return or not-that is driven by a need for mutual survival. ${ }^{45}$ But relationships quickly return to pre-disaster patterns, following modern ethos of privacy and individualistic self-sufficiency with the expectation of more balanced reciprocity when the threat is removed. ${ }^{45}$ However, there may be some added benefit to sustaining this collective approach by building social capital among neighbors. ${ }^{23}$ Building social connections and resources for older adults disconnected within their communities may diminish the vulnerability that some older adults face and promote longerterm recovery for individuals and communities. For example, efforts such as those conducted through PROSPER, a multifaceted, collaborative community-level intervention designed to draw upon evidence-based prevention programs to build social capital, may offer insight into how to build lasting social relations among communities for older persons. ${ }^{46}$ Additional efforts that build connections through shared experiences, such as community gardening or celebrations, may further augment individuals' access to a network in times of need. ${ }^{47}$ Further work is needed to test and implement systematic models for building such connections for older adults.

Overall, this work is strengthened by its use of ground-up research methodologies that allow the voice of the participant to guide all analytic inferences. However, the study is not without limitations. First, the generalizability of results is limited to older adults in New Jersey who reported "a lot" of primary home damage following Hurricane Sandy and were members of the ORANJ BOWL research panel. The majority of participants were white and women. As a result, the findings may be restricted to the experiences of these individuals. More could be learned by studying the associations tested here in a larger sample in other geographic regions following other natural disasters, other demographic groups, or with older adults who experienced secondary home damage. Second, this work does not link support received with quantitative assessment of home damage, individuallevel outcomes (ie, physical or mental health), or indicators of resilience. Additional work should explore the impact of specific types of support received on psychosocial outcomes for the older person both qualitatively and quantitatively. Third, examining such processes with a larger-scale, quantitative empirical design may shed further light on systematic associations of challenges faced and subsequent types of support received. Furthermore, not addressed here are the characteristics of older adults that make them more or less dependent on others for support or the characteristics related to change in neighborhood attitudes. It may be that individuals with higher levels of financial constraints, less individual cognitive coping capacity, or in specific locations draw upon neighbor support differentially. Additional research should explore these processes further to refine our understanding of where supports are most needed. In addition, this work did not explore the weight or meaning of specific types of challenges as more or less dominant in shaping the responses of individuals; for example, a specific financial challenge, although discussed less, could drive one's actions more than other challenges faced. Finally, this work asked participants at one point in time to describe their experiences before, during, and after the storm. Developing rapid research funding mechanisms that allow for the initiation of longitudinal designs that assess participants immediately following a storm and then include subsequent real-time assessment of the process through which support is evoked would be meaningful. 


\section{CONCLUSIONS}

Overall, findings from this work add to our understanding of the challenges older adults face during a disaster and specify to whom older adults turn for support before, during, and after a natural disaster. Building an older adult's traditional social network of family and friends in addition to their larger community support system may be key to promoting resilience and buffering against potential vulnerability in older adulthood. Public health efforts that seek to build the social support resources available to older adults may be critical for individual-level and ultimately community resilience.

\section{About the Authors}

New Jersey Institute for Successful Aging, Rowan University School of Osteopathic Medicine, Stratford, New Jersey (Dr Heid, Ms Cartwright, Dr Pruchno), and Department of Sociology $\mathcal{E}$ Anthropology, Rowan University, Glassboro, New Jersey (Dr Schug).

Correspondence and reprint requests to Allison R. Heid, PhD, 42 E Laurel Rd, Stratford, NJ, 08084 (E-mail: heid@rowan.edu).

\section{Acknowledgments}

The authors extend their appreciation to the research staff who collected these data and the participants who completed the interviews. We also thank Sneha Kolla and Christopher Carey for their work in supporting data analysis.

\section{Funding}

This work was supported by funding from the Assistant Secretary for Preparedness \& Response (HITEP130008; "Social Capital and Resilience of Older People Exposed to Hurricane Sandy").

Published online: October 14, 2016.

\section{REFERENCES}

1. Miles K. Superstorm: Nine Days inside Hurricane Sandy. New York, NY: Penguin Group; 2014.

2. Brackbill RM, Caramanica K, Maliniak M, et al. Nonfatal injuries 1 week after Hurricane Sandy. MMWR Morb Mortal Wkly Rep. 2014; 63(42):950-954.

3. US Department of Commerce. Service Assessment Hurricane/Post-Tropical Cyclone Sandy, October 22-29, 2012. http://www.nws.noaa.gov/os/assessments/ pdfs/Sandy13.pdf. Published May 2013. Accessed February 25, 2016.

4. Mapping Hurricane Sandy's deadly toll. The New York Times. http:// www.nytimes.com/interactive/2012/11/17/nyregion/hurricane-sandymap.html Published November 17, 2012. Accessed February 25, 2016.

5. Baltes PB, Smith J. New frontiers in the future of aging: from successful aging of the young old to the dilemmas of the fourth age. Gerontology. 2003;49(2):123-135. http://dx.doi.org/10.1159/000067946.

6. Acierno R, Ruggiero KJ, Kilpatrick DG, et al. Risk and protective factors for psychopathology among older versus younger adults after the 2004 Florida hurricanes. Am J Geriatr Psychiatry. 2006;14(12):1051-1059. http://dx.doi.org/10.1097/01.JGP.0000221327.97904.b0.

7. Kun P, Tong X, Liu Y, et al. What are the determinants of post-traumatic stress disorder: age, gender, ethnicity or other? Evidence from 2008 Wenchuan earthquake. Public Health. 2013;127(7):644-652. http://dx. doi.org/10.1016/j.puhe.2013.04.018.

8. Roberto KA, Kamo Y, Henderson T. Encounters with Katrina: dynamics of older adults' social support networks. In Cherry KE, ed. Lifespan Perspectives on Natural Disasters. New York, NY: Springer; 2009:133-152. http://dx.doi.org/10.1007/978-1-4419-0393-8_7.
9. Adams RE, Boscarino JA. Predictors of PTSD and delayed PTSD after disaster: the impact of exposure and psychosocial resources. J Nerv Ment Dis. 2006;194(7):485-493. http://dx.doi.org/10.1097/01.nmd. 0000228503.95503.e9.

10. Watanabe C, Okumura J, Chiu T, et al. Social support and depressive symptoms among displaced older adults following the 1999 Taiwan earthquake. J Trauma Stress. 2004;17(1):63-67. http://dx.doi.org/ 10.1023/B:JOTS.0000014678.79875.30.

11. Fingerman KL, Pitzer LM, Chan W, et al. Who gets what and why? Help middle-aged adults provide to parents and grown children.J Gerontol B Psychol Sci Soc Sci. 2011;66B(1):87-98. http://dx.doi.org/10.1093/ geronb/gbq009.

12. Norris FH, Friedman MJ, Watson PJ, et al. 60,000 Disaster victims speak: part I. An empirical review of the empirical literature, 1981-2001. Psychiatry. 2002;65(3):207-239. http://dx.doi.org/10.1521/psyc.65. 3.207.20173.

13. Henderson TL, Roberto KA, Kamo Y. Older adults' responses to Hurricane Katrina: daily hassles and coping strategies. J Appl Gerontol. 2010;29(1):48-69. http://dx.doi.org/10.1177/0733464 809334287.

14. Langan JC, Palmer JL. Listening to and learning from older adult Hurricane Katrina survivors. Public Health Nurs. 2012;29(2):126-135. http://dx.doi.org/10.1111/j.1525-1446.2011.00996.x.

15. Ardalan A, Mazaheri M, Naieni KH, et al. Older pepople's needs following major disasters: A qualitative study of Iranian elders' experiences of the Bam earthquake. Ageing Soc. 2010;30(1):11-23. http://dx.doi.org/10.1017/S0144686X09990122.

16. Brunkard J, Namulanda G, Ratard R. Hurricane Katrina deaths, Louisiana, 2005. Disaster Med Public Health Prep. 2008;2(4):215-223. http://dx.doi.org/10.1097/DMP.0b013e31818aaf55.

17. Knight BG, Gatz M, Heller K, et al. Age and emotional response to the Northridge Earthquake: a longitudinal analysis. Psychol Aging. 2000; 15(4):627-634. http://dx.doi.org/10.1037/0882-7974.15.4.627.

18. Norris FH, Byrne CM, Diaz E, et al, Psychosocial resources in the aftermath of natural and human-caused disasters: A review of the empirical literature, with implications for intervention. http://www. westga.edu/ vickir/Healthcare/HC14\%20FacititatingResiliency/Link\% 207\%20_\%20NCPTSD\%20Psychosocial\%20Resources.pdf. Published May 22, 2007. Accessed February 25, 2016.

19. Xu J, Wu Z. One-year follow-up analysis of cognitive and psychological consequences among survivors of the Wenchuan earthquake. Int J Psychol. 2011;46(2):144-152. http://dx.doi.org/10.1080/00207594. 2010.529908.

20. Preville M, Lamoureux-Lamarche C, Vasiliadis H-M, et al. The 6-month prevalence of posttraumatic stress syndrome (PTSD) among older adults: validity and reliability of the PTSD scale. Can J Psychiatry. 2014;59:548-555.

21. Xu J, Song X. Posttraumatic stress disorder among survivors of the Wenchuan earthquake 1 year after: prevalence and risk factors. Compr Psychiatry. 2011;52(4):431-437. http://dx.doi.org/10.1016/ j.comppsych.2010.08.002.

22. Norris FH, Kaniasty K, Conrad MI, et al. Placing age differences in cultural context: A comparison of the effects of age on PTSD after disasters in the United States, Mexico, and Poland. J Clin Geropsychol. 2002;8(3):153-173. http://dx.doi.org/10.1023/A:1015940 126474.

23. Heid AR, Christman Z, Pruchno R, et al. Vulnerable, but why? Posttraumatic stress symptoms in older adults exposed to Hurricane Sandy [published online March 28, 2016]. Disaster Med Public Health Prep. 2016;10(03):362-370. http://dx.doi.org/10.1017/dmp.2016.15.

24. Krause N. Stress and sex differences in depressive symptoms among older adults. J Gerontol. 1986;41(6):727-731. http://dx.doi.org/10.1093/ geronj/41.6.727.

25. Pearlin LI, Mullan JT, Semple SJ, et al. Caregiving and the stress process: an overview of concepts and their measures. Gerontologist. 1990; 30(5):583-594. http://dx.doi.org/10.1093/geront/30.5.583. 
26. Shenk D, Ramos B, Kalaw KJ, et al. History, memory, and disasters among older adults: a life course perspective. Traumatology. 2009; 15(4):35-43. http://dx.doi.org/10.1177/1534765609359729.

27. Heid AR, Pruchno R, Cartwright FP, et al. Exposure to Hurricane Sandy, neighborhood collective efficacy, and posttraumatic stress symptoms in older adults [Published online February 25, 2016]. Aging Ment Health. 2016:1-9. http://dx.doi.org/10.1080/13607863.2016.1154016.

28. Cagney KA, Wen M. Social capital and aging-related outcomes. In Kawachi I, Subramanian SV, Kim D, eds. Social Capital and Health. New York, NY: Springer Science and Business Media; 2008:239-258. doi: 10.1007/978-0-387-71311-3_11.

29. Feldman PJ, Steptoe A. How neighborhoods and physical functioning are related: the roles of neighborhood socioeconomic status, perceived neighborhood strain, and individual health risk factors. Ann Behav Med. 2004;27(2):91-99. http://dx.doi.org/10.1207/s15324796abm2702_3.

30. Goldman L, Finkelstein R, Schafer P, Pugh T. Resilient Communities Report. New York, NY: New York Academy of Medicine; 2014.

31. Johns LE, Aiello AE, Cheng C, et al. Neighborhood social cohesion and posttraumatic stress disorder in a community-based sample: Findings from the Detroit Neighborhood Health Study. Soc Psychiatry Psychiatr Epidemiol. 2012;47(12):1899-1906. http://dx.doi.org/10.1007/s00127012-0506-9.

32. Kawachi I, Subramanian SV, Kim D. Social capital and health: a decade of progress and beyond. In Kawachi I, Subramanian SV, Kim D, eds. Social Capital and Health. New York, NY: Springer Science and Business Media; 2008:1-26. http://dx.doi.org/10.1007/978-0-38771311-3 1.

33. Associated Press-NORC Center for Public Affairs Research. Two years after Superstorm Sandy: Exploring resilience in twelve neighborhoods. www.apnorc.org/pdfs/sandy/sandy\%20phase\%202\%20report_final.pdf. Published October 27, 2014. Accessed February 25, 2016.

34. Bauman J. Older Adults and Their Recollections of September 11, 2001. [dissertation]. New York: New York University; 2008.

35. Kamo Y, Henderson TL, Roberto KA, et al. Perceptions of older adults in a community accepting survivors of Hurricane Katrina. Curr Psychol. 2015;34(3):551-563. http://dx.doi.org/10.1007/s12144015-9356-4.
36. Miller E, Brockie L. The disaster flood experience: older people's poetic voices of resilience. J Aging Stud. 2015;34:103-112. http://dx.doi.org/ 10.1016/j.jaging.2015.05.003.

37. Stanko KE, Cherry KE, Ryker KS, et al. Looking for the silver lining: benefit finding after Hurricanes Katria and Rita in middle-aged, older, and oldest-old adults. Curr Psychol. 2015;34(3):564-575. http://dx.doi. org/10.1007/s12144-015-9366-2.

38. Touhy R, Stephens C, Johnston D. Older adults' disaster preparedness in the context of the September 2010-December 2012 Canterbury earthquake sequence. Int J Disaster Risk Reduct. 2014;9:194-203. http://dx.doi.org/10.1016/j.ijdrr.2014.05.010.

39. Pruchno RA, Wilson-Genderson M, Cartwright F. A two-factor model of successful aging. J Gerontol Psychol Sci. 2010;65B(6):671-679. http://dx.doi.org/10.1093/geronb/gbq051.

40. Graneheim UH, Lundman B. Qualitative content analysis in nursing research: concepts, procedures and measure to achieve trustworthiness. Nurse Educ Today. 2004;24(2):105-112. http://dx.doi.org/10.1016/ j.nedt.2003.10.001.

41. Marks LD. A pragmatic, step-by-step guide for qualitative methods: capturing the disaster and long-term recovery stories of Katrina and Rita. Curr Psychol. 2015;34(3):494-505. http://dx.doi.org/10.1007/s12144-015-9342-x.

42. Glaser BG. The constant comparative method of qualitative analysis. Soc Probl. 1965;12(4):436-445. http://dx.doi.org/10.2307/798843.

43. Araya R, Dunstan F, Playle R, et al. Perceptions of social capital and the built environment and mental health. Soc Sci Med. 2006; 62(12):3072-3083. http://dx.doi.org/10.1016/j.socscimed.2005.11.037.

44. Baum FE, Ziersch AM. Social capital. J Epidemiol Community Health. 2003;57(5):320-323. http://dx.doi.org/10.1136/jech.57.5.320.

45. Rao L-L, Han R, Ren X-P, et al. Disadvantage and prosocial behavior: the effects of the Wenchuan earthquake. Evol Hum Behav. 2011;32 (1):63-69. http://dx.doi.org/10.1016/j.evolhumbehav.2010.07.002.

46. Chilenski SM, Ang PM, Greenberg MT, et al. The impact of a prevention delivery system on perceived social capital: the PROSPER Project. Prev Sci. 2014;15(2):125-137. http://dx.doi.org/10.1007/s11121-012-0347-5.

47. Alaimo K, Reischl TM, Allen JO. Community gardening, neighborhood meetings, and social capital. J Community Psychol. 2010;38(4):497-514. http://dx.doi.org/10.1002/jcop.20378. 